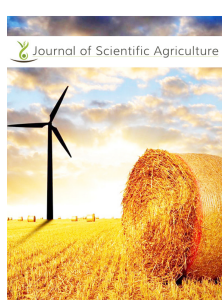

ISSN: 2184-0261

\title{
Raiding of agricultural crops and forests by wild boar (Sus scrofa L.) and its mitigation tricks
}

\author{
Muhammad Sarwar* \\ Agricultural Biotechnology Division, National Institute for Biotechnology and Genetic Engineering (NIBGE), \\ Faisalabad-44000, Punjab, Pakistan.
}

\begin{abstract}
Wild boar (Sus scrofa L.), is the utmost communal native species of wildlife to bring about plants injury. In this article, it is proved that wild boar is an important factor and a particular concern to the agricultural industry regarding crops and frosts damage along with its alleviating tactics. Wild boar may destroy to agricultural crops by crushing or eating of plants. Likewise, these may harm to crops while wallowing and rooting which injury to plant roots, and form holes and grooves that harm farm equipment and endanger operations. Wild boar injury is more in fields that are in neighboring vicinity of forests ranges. Wild boars harshly influence trees and timber resources in many ways like disturbance of planted seedlings, girdling and rubbing of matured trees, chewing and rooting of sideway roots of fully-fledged trees, and tusking or scent marking with the tusk glands that injuries to tree bark. Mitigation strategies for wild boar losses comprise creation of education and awareness among persons, co-operative securing of matured crops and use of local protective methods. Wild boar can be managed through small-scale exclusion, trapping and shooting tactics. Shooting is a popular method of controlling wild boar populations and in this way pressure from hunting will let the pest to move away from where they are hunted, or at a minimum, will restrict their movements. It has been found that using of dogs is the most effective for locating of individuals or smaller groups of wild boars. In some cases, a female boar is trapped, spayed fitted with a radio collar and then released in field. Since female boars live in groups, the spayed female will lead wildlife managers to local boar populations, which can assist in population control efforts. While recreational hunting is often a preferred method, it is also effective to some extent at controlling of wild boar population growth. Trapping, however, is highly effective at controlling and reducing of boar's population growth. The study of spatiotemporal variant of boar-inflicted losses and recognition of reasons which boost the risk of harm delivers necessary facts for contributing to develop a further effectual strategy for handling of wild boar's density.
\end{abstract}

Received: September 29, 2018 Accepted: December 12, 2018 Published: January 19, 2019

*Corresponding Author: Muhammad Sarwar Email: drmsarwar64@gmail.com
KEYWORDS: Wildlife damage management, vertebrate pest, wild pig, agricultural crops, frosts, damage mitigation

\section{INTRODUCTION}

In the course of the recent times, in certain cases, vertebrate pest fauna mainly consisting of mammals by way of distinctive mention to wild boars and monkeys, have initiated a huge damage to agricultural production [1-3]. The wild boar (Sus scrofa L.), is one of the utmost broadly spread ungulates and large mammals pest in the biosphere owing to its great multiplicative speed, adaptableness, and resourceful nourishing [4]. In several dwellings, wild boars are deliberated a pest species for the reason that these harm to foodstuff crops as well as spread infections to livestock and human [5], cause traffic accidents [6] and undesirably influence on native flora and fauna [7]. The incidence of plants or crops injury by wild boars has been outstretched theatrically in the previous sometimes, suggesting an upsurge in social conflicts, expenses for advantage and a danger to natural environment [8].
As an over-all picture of farming destruction produced as a result of wild boar $S$. scrofa, the injury events mostly involve in vineyards, oat fields and pastures, and are described by a topmost commonness in summertime and initial autumn, and a least in spring. Injured areas are considered through a rising in existence of stable crops, a declining occurrence of woods, marquise and city spaces, and a condensed space from accommodation parts (forests and shrub lands) [9].

Over 400 species of plants have been recorded in the wild boar's diet, among which, 40 species are crop plant. The injury produced through wild boar is further upsetting than their real nourishing in the crop [10]. Unlike other pests, wild boars usually result loss right from seedling commencing till to the crop maturity [11].

The great multiplicative degree of species pooled by its possibility to impose loss to food production is the reason of a 
human-wildlife clash that will rise in concentration by means of the wild boar inhabitants raise greater. Owing to facing of enlarged harmful influence attributable to wild boar, scientists and wildlife administrators are examining for operative stoppage and alleviation approaches [12]. Therefore, the fundamental purpose of this interpretation is to determine loss and afterward the control of wild boar on cultivated and forest plants.

\section{Damage to Crops by Wild Boars}

In a lot of states, the wild boar (S. scrofa) is frequently linked with significant crop losses. Injuries to crops are usually initiated as a result of ungulates and single species in specific which is linked by way of crop injury is the wild boar (S. scrofa). In comparison to several other ungulates, the wild boar is an omnivore and inhabits a vast range of habitats [13]. It can be found on all continents except Antarctica. This one omnivorous activities permits it to get a feel for well to its environment and diet to a great degree is subjective through whatever is existing [14].

Anyplace boars are existing, these come to be a problematic, beginning harm to livestock, threatening native wildlife, forests and the environment, and agricultural fields. Wild boar damage is mostly impacted by safety and forage-related factors; safety factors include human occurrence and the space to the edge of the adjacent roads, rivers and forests, whereas forage-related factors contain creation of seeds by deciduous forests, and the kind, plenty, growth time and accessibility to cultivated crops [15]. Wild pigs causes lots of damages to agricultural crops worldwide which includes almost all field crops [16].

Damage due to wild boar in everlasting grassland is far more numerous and intense than destruction to yearly crops, trichomatous crops like barley are escaped, injury is seasonally scattered with respect to nature of crop, loss is dispersed spatially in a non-uniform way, harm amount is considerably linked with wild boar pursuing bags both over time and space [17]. This risk assessment has shown that wild boars are a particular concern to the agricultural industry regarding crops and frosts damage.

\section{Damage to Trees and Forests}

The presence of wild boars in a hardwood forest can inhibit and even stop forest regeneration. Hard mast such as acorns, hickory nuts and beach nuts are seasonally important food sources for wild boars, and they leave very few to germinate and grow into future mast bearing trees. Any mast that does germinate and begins growth is often consumed by boars shortly thereafter. In pine plantations boars will root up pine seedlings and consume the roots. This sort of damage can cost to timber companies and private plantation owners can cause millions of dollars losses in future timber sales. Other damage caused by wild boars in forests is triggered by scent marking. Boars often use hardwood and pine saplings to mark territory. Damage is done through tusking and rubbing, and both of these activities remove the bark from trees by exposing them to harmful insects and pathogens. The presence of wild boars in a forested system can also lead to a decrease in animal diversity. This is due in part to the competition for resources and the reduction in available habitat. The space use patterns vary by age class of boars, by piglets have a preference to forest central areas, whereas fullygrown males are vigorous nearby the villages. Of its own accord, managing the population of adult male is the best straight way to deal with crop invading fears [18].

Generally, mast is the botanical name for the seeds, nuts, buds, or fruits of plants and trees which are consumed by means of wildlife. Commonly, there are two key kinds of mast, soft mast comprises fruits and berries, for example, blueberries, serviceberries and crabapples, while hard mast contains hard seeds and nuts, for instance, walnuts, acorns and hickory nuts. Individually, both forms are significant year-round diet sources for wildlife, however, hard mast is frequently deliberated very essential, particularly by way of a winter diet source, owing to its greater energy portion. The designation of mast is occasionally as well stretched to comprise the winged seeds of trees like elm and maple, along with nuts and pine seeds, and even buds, hips and catkins such as rose hips. Beechnuts, acorns, hickory nuts and further hard mast are a key diet source for wild boars, leaving very rare to develop into new trees in areas with high boar populations. Within the coastal plain regions, boars pull up longleaf pine plantlets and eat the soft roots that are rich in carbohydrates. Wild boars consume seedlings and even developed plants of both hardwoods and pines for rubbing objects and scent marking posts. The severe irritation might harm to bark layers, parting the tree vulnerable to pathogens and harmful insects. Injury to established plantlets is the peak extensive and expensive forest harm as a result of feral boars. The grass stage of longleaf pine is mostly vulnerable to boars rooting and chewing. Feeding of forage and pasture species similarly proposes probable competition for pasture with home stock. Alike injury by feral boars has been described for planted hardwood seedlings [19].

\section{Signs of Wild Pigs}

From time to time, landlords do not understand that they have wild boars on their possessions till they really watch a boar or up until the loss is extensive. The earlier the occurrence of wild boars is noticed and control actions started, the well it is. The significant signs of wild boars are rooting, tracks, trails, nests or beds, wallows, as well as trees damage and post rubs [20].

\section{Methods for Monitoring Crop Damage by Wild Boar}

This article compares three different survey methods for monitoring of wild boar (S. scrofa) injury to farming crops. The first method investigated is also the most conventional and involves walking through the fields on foot to locate and measure patches of wild boar damage. This method in comparison to a second involves the use of a remotely controlled aerial drone which takes digital photographs of the fields. These photographs are then analyzed and observed damaged areas are recorded. The third method considers the theory that most wild boar damage to crops occurs on the edge of the fields, in order to determine 
if a relationship exists between the damage on field edges and the total damage in the whole field. The premise of this is based on the theory that using an edge index would increase efficiency since only the field edges needed to be physically inspected. These methods are compared in regards to time and cost efficiency. The cost of the aerial survey method has been calculated to be more/ha, whereas the ground method cost less/ha. The aerial method takes less time compared to the ground method with a time cost of $0.28 \mathrm{~h} / \mathrm{ha}$ compared to $0.34 \mathrm{~h} / \mathrm{ha}$. The edge index for the third method does not show any consistent relationship between fields so could not be further utilized. In decision, the aerial method is too costly to provide a suitable alternative to the ground method and evidence suggests that the ground method is more accurate in distinguishing wild boar damage from that caused by other game species [21].

\section{Using of Drones to Estimate Crop Damage}

A method by using of drones to estimate crop damage due to wild boar has been developed, which is affordable and easy to apply. It usages a typical commercial drone to proceed for above ground photographs of injured cultivated fields that are analyzed by an algorithm identifying spoiled area. A smartphone is connected to the remote controller of drone that permits to perceive the camera visualization of the drone. Injury is certainly perfect on the camera, in maize arenas boars move over the maize that makes that observers have areas in a normally green covered maize field with holes in the coverage of broken stems. In grasslands, rooting bases a perfect color variance with grass for the reason that the soil is rooted up. For a specific field, several distinct photographs with $75-85 \%$ overlap are taken. The great overlap allows combining the separate photographs in a lone image corrected for the diverse perspectives and displaying the whole field. The part of the field is then categorized into injured and un-injured portions by means of object based image investigation. The algorithm touches $93 \%$ of precision for maize fields and $94 \%$ accuracy for grasslands. Conventionally, crop loss is assessed by qualified specialists by computing the spoiled part in the field. Flying and taking photographs of spoiled fields does not take as long as doing a calculation through ground visit, which also makes it cost-effective. An additional benefit is that the technique is standardized, which allows a straight evaluations between diverse fields and over time [22-23].

\section{Management of Wild boars}

Facing of growing harmful influences attributable to wild boar, scientists and wildlife administrators are examining for operational avoidance and alleviation approaches. Wild boar densities may be coped through nonlethal or lethal means [24].

\section{Trappings}

The maximum effectual means for eliminating wild boars is trapping for the reason that it is a constant action needing far a reduced amount of time and work than other approaches, for instance, hunting. A successful boar trapping pivots upon more than a few following important machineries.

\section{Scout for Boar Activity}

The site at which wild boar damage has occurred is not always the best location for a trap. Wild boars habitually pass abundant of their time in covered parts of dense refuge nearby to a water source. As a result, creek bottoms and river, and other low-lying zones must be searched initially for boar's activity. Locating of traps along travel routes leading to and from these loafing and staging areas will result in greater catch opportunities. Though this fact may appear apparent, several trappers create an error of choosing expanses wherever they consider that boars should be and not anywhere the boars really are [25].

\section{Bait to Attract Boars}

Once landowners have traced an area with plentiful boars sign, they do not instantly require to install up trap. As an alternative, should launch a lured 'scouting site' to decide whether or not wild boars are keenly using the area. Landowners can aid to appeal wild boars to their bait sites by coating the bait by sorghum molasses, an alike sugary sensing sweet liquid, or viable bait topper, and one more choice is to usage fermented corn. Landowners require to reexamine the location every day to decide if boars have located the bait. Based upon on the dimension of their possessions and the space among sites with current boars activity, landowners might need to create a number of of these scouting sites to decide which locations boars are keenly using. As soon as landowners have recognized an active site, arrange a trap and launch pre-baiting. Everywhere possible, landowners must launch their trap location on properly level ground, in a sheltered expanse upwind of bedding and loafing zones, and in locations where vehicles can access. Confirming vehicle contact near to the trap location will save labor and time in creating, baiting and scrutiny the trap, and too in eliminating of boars carcasses from the trap [26].

\section{Pre-baiting}

Pre-baiting is a vital element to fruitful boars catching, yet it is frequently ignored by trappers. Pre-baiting invites boars to the trap location, and further notably, acquires entirely of the boars in a sounder or family group conditioned to enter and leave the trap undamaged. Trail cameras are precisely valuable for accompanying round-the-clock observation of pre-baited traps and take the estimation at what time to set the trap. Typically, 1 to 2 weeks of pre-baiting is essential before the whole sounder will move in the trap. Still, 2 weeks can pass and some boars still might not have move in the trap [27].

Some boars in a sounder primarily do not feel at ease for arriving a trap and will halt outdoor whereas others freely move in and forage on the bait. This trap-shyness is particularly accurate for older boars and boars that have been earlier caught and relieved into the wild. It is essential to be patient and permit whole of the boars to come to be accustomed to securely ingoing and outgoing the trap prior to it is set. Boar is a clever creature, and if the trap is set too rapidly, participants of the sounder to which landowners do not fastening will have become accomplished 
and may be further challenging, if not impossible, to arrest later. For dealing with trap-shyness, landowners may want to eliminate the door from the trap and make a larger opening until boars develop accustomed to frequently incoming and exit the trap. Likewise, a larger trap may look fewer limiting to trap-shy boars [28].

\section{Choosing of a Bait}

Before landowners pre-bait or bait any boars or boars traps, be assured to check the baiting guidelines relating to the state in which they will be carrying these actions. Wild boars in many areas can choose one kind of bait over another, nevertheless, the bait that can be used by themselves or in grouping are sweet potatoes, shelled corn (dry or fermented), or other grains, overripe fruits, molasses and commercial scents or attractants [29, 30].

\section{Hunting}

Gunfire and hunting are greatest used as balances to a severe trapping package and not as the main means of elimination. In some cases, shooting and hunting have been demonstrated operative for managing of wild boars, however, these approaches need a noteworthy quantity of time and struggle, and it is infrequent for these to be active in significantly decreasing boars amounts. To uphold burden on wild boar densities, natural resource managers and landowners frequently include nighttime controlling actions to carry on their combat against pest. Among various types of night hunting, rifle and spotlight can illuminate boars out to 100 meters, best used in open habitats, better vision when used in bright moonlight, very difficult and success rates are low. Night vision optics can detect boars from several hundred meters, allows landowners to take close shots, increases chances of numerous shots from operative ranges, price of worth products is prohibitive and works in multiple habitat types. Thermal imaging devices notice heat set off by all items in environment and yield a gray-scale visual image of the heat variances. Animals look in contradiction of a gray background as if illumined through a white light. It can detect animals at more than $1 / 2$ kilometer away, does not work well in heavy forest cover, works best in open habitats and cost is prohibitive [31].

\section{Using of Dogs}

For hunting by dogs may be effective in many circumstances, but this technique is unsuccessful in eliminating of huge amounts of boars. Although trapping is the best effectual means of eradicating boars from a region, dog hunting is the greatest operational means to get rid of trap-shy or educated boars that have transformed their action outlines built on earlier skill with traps. Nowadays, boars hunting through dogs has grown into a very widespread method of sport hunting. Even though this technique of hunting is from time to time controversial, it helps as a prized device while demanding to eliminate boars in areas where extreme gunfire and catching stress have compelled boars to develop further nightly in their activity patterns [32-34].

\section{CONCLUSIONS AND RECOMMENDATIONS}

Among vertebrate pests, wild boar has turned out to be a consistent threat to agriculturalists in case of most important plants causing into massive losses. The intention of this article is to deliver an overall sketch of agrarian and forestry injuries triggered by wild boar S. scrofa. Destruction by boars is not new and anywhere these pests are present, they certainly turn out to be a problematic. The occurrence of destruction is highly greater in crop fields neighboring to forestry expanses, and this consequences into uninterrupted clash among wild boar and people. Wild boars eat and crush crops, and their wallowing and rooting activities additionally harm to crop areas. Wallowing and rooting make furrows and holes which certainty if overlooked, may harm to agricultural tools and pose a danger to equipment workers. Wild boars may harm equally to hardwood and pine trees through using these as rubbing supports. Strong irritation and injury to the bark layers can permit trees further susceptible to pathogens (bacteria, fungi and viruses) and harmful insects. Wild boars may destroy to pine plantations and natural regeneration expanses by rooting, direct feeding and crushing, particularly in longleaf pine (Pinus palustris) plantlets. The methods for stopping or decreasing of injury as a result of wild boars must be further directed in time and space and that amendments to cropping outlines should essentially add on the way to a decline of wild boar injury. Obviously, eradicating or even lowering of a wild boar population to an acceptable level is quite expensive, difficult to achieve and difficult to maintain. The manpower should be employed by the farmers for protecting of the crop damage by the wild boar, which can be helping only to some extent. Hence, there is a need for evolving of suitable eco-friendly techniques for minimizing of the crop damage by wild boars to increase production and productivity of various crops, and also reduce the man and animal conflict. Certainty, when single and neighboring farm landlords cooperatively effort jointly to decrease density size of pest, then entire approaches of control are simply operative for long-lasting, otherwise, even the utmost effectual wild boars elimination plans will undergo frequent reinvasion from adjoining inhabitants.

\section{REFERENCES}

1. Sarwar, M. The Rodents (Mammalia: Rodentia) - Gnawing Away on Crops and Options for the Integrated Pest Management at Field. American Journal of Marketing Research 2015; 1 (3): 136-141.

2. Sarwar, M. Pattern of Damage by Rodent (Rodentia: Muridae) Pests in Wheat in Conjunction with Their Comparative Densities throughout Growth Phase of Crop. International Journal of Scientific Research in Environmental Sciences 2015; 3 (4): 159-166.

3. Sarwar. M. The Rodents (Mammalia: Rodentia) - Gnawing Away on Stored Grains and Options for the Integrated Pest Management in Stores. American Journal of Food Science and Health 2016; 2 (6): 161-168.

4. Ballari, S. A. and Barrios-García, M. N. A review of wild boar Sus scrofa diet and factors affecting food selection in native and introduced ranges. Mammal. Rev 2014; 44: 124-134.

5. Meng, X., Lindsay, D. and Sriranganathan, N. Wild boars as sources for infectious diseases in livestock and humans. Philos. Trans. R. Soc. Lond. B. Biol. Sci 2009; 364: 2697-2707.

6. Colino-Rabanal, V. J., Bosch, J., Munoz, M. J. and Peris, S. J. Influence of new irrigated croplands on wild boar (Sus scrofa) road kills in NW Spain. Anim. Biodivers. Conserv 2012; 35: 247-252. 
7. Engeman, R. M., Duffiney, A., Braem, S., Olsen, C., Constantin, B., Small, P., Dunlap, J. and Griffin, J. C. Dramatic and immediate improvements in insular nesting success for threatened sea turtles and shorebirds following predator management. J. Exp. Mar. Biol. Ecol 2010; 395: 147-152.

8. Amici, A., Fioravante, S., Carlo, M. R. and Riccardo, P. Increase in crop damage caused by wild boar (Sus scrofa L.): the "refuge effect". Agronomy for Sustainable Development 2012; 32 (3): 683-692.

9. Lombardini, M., Lombardini, A. M. and Alberto, F. Factors influencing wild boar damage to agricultural crops in Sardinia (Italy). Current Zoology 2017; 63 (15): 507-514.

10. Chauhan, N. P. S. and Rajpurohit, K. S. Survey of Animal Damage Problem in and around protected areas and managed forests: Phase- I Madhaya Pradesh, Bihar and Orissa - A Report, Wildlife Institute of India, Dehradun. 1993.

11. Groot-Bruinderinck, G. W. T. A., Hazebrook, E. and Van der Voot, H. Diet and condition of wild boar (Sus scrofa scrofa) without supplementary feeding. J. Zool. Soc. London 1994; 233: 631-648.

12. Rao, V. V., Naresh, B., Reddy, V. R., Sudhakar, C., Venkateswarlu, P. and Rao, D. R. Traditional management methods used to minimize wild boar (Sus scrofa) damage in different agricultural crops at Telangana state, India. International Journal of Multidisciplinary Research and Development 2015; 2 (2): 32-36.

13. Baskin, L. and Danell, K. Ecology of ungulates: A handbook of species in eastern Europe and northern and central Asia. Springer-Verlag, Berlin. 2003: 15-37.

14. D'Huart, J. P. Habitat utilization of old world wild pigs. In: Herrero, H., Irizar, I., Laskurain, N. A., García-Serrano, A., \& García-González, R. 2005. Fruits and roots: wild boar foods during the cold season in the southwestern Pyrenees. Italian Journal of Zoology 1991; 72: 49-52.

15. Chauhan, N. P. S. Human casualties and agricultural crop raiding by wild pigs and mitigation strategies in India. The $8^{\text {th }}$ European Vertebrate Pest Management Conference, Julius-Kuhn-Archiv 2011; 432: 192-193.

16. Thurfjell, H., Ball, J. P., Ahlen, P.A., Kornacher, P., Dettki, H. and Sjoberg, K. Habitat use and spatial patterns of wild boar Sus scrofa (L.): agricultural fields and edges - European Journal of Wildlife Research 2009; 55: 517-523.

17. Schley, L., Dufrene, M., Krier, A. and Frantz, A. C. Patterns of crop damage by wild boar (Sus scrofa) in Luxembourg over a 10-year period. European Journal of Wildlife Research 2008; 54: 589-599.

18. Guo, W., Cao, G. and Quan, R. C. Population dynamics and space use of wild boar in a tropical forest, Southwest China. Global Ecology and Conservation 2017; 11: 115-124.

19. Gentle, M., Speed, J. and Marshall, D. Consumption of crops by feral pigs (Sus scrofa) in a fragmented agricultural landscape. Australian Mammalogy 2015; 37 (2): 194-200.
20. Hamrick, B., Campbell, T., Higginbotham, B. and Lapidge, S. Managing an Invasion: Effective Measures To Control Wild Pigs. USDA Nationa Wildlife Research Center - Staff Publications. 1300. The Wildlife Professional 2011: 41-42.

21. Giuliano, W. M. Wild Hogs in Florida: Ecology and Management. Department of Wildlife Ecology and Conservation, University of Florida/ Institute of Food and Agricultural Sciences, Extension Service. 2016: 9

22. Zhang, C. and Kovacs, J. M. The application of small unmanned aerial systems for precision agriculture: a review. Precision Agriculture 2012; 13: 693-712.

23. Puig, E., Gonzalez, F., Hamilton, G. and Grundy, P. Assessment of crop insect damage using unmanned aerial systems: A machine learning approach. The $21^{\text {st }}$ International Congress on Modelling and Simulation, Gold Coast, Australia, 29 Nov to 4 Dec 2015. 2015; 1420-1426.

24. Schlageter, A. and Haag-Wackernagel, D. Evaluation of an odor repellent for protection crops from wild boar damage. Journal of Pest Science 2012; 85: 209-215.

25. Hamrick, B., Smith, M. D., Jaworowski, C. and Strickland, B. A Landowner's Guide for Wild Pig Management: Practical Methods for Wild Pig Control. Extension Service of Mississippi State University 2011: 43.

26. Higginbotham, B. Chumming - Feral Hogs. Quality Whitetails magazine (June-July) 2011: 22-29.

27. Bieber, C., and Ruf, T. Population dynamics in wild boar Sus scrofa: ecology, elasticity of growth rate and implications for the management of pulsed resource consumers. Journal of Applied Ecology 2005; 42: 1203-1213

28. Magnusson, M. Population and management models for the Swedish wild boar (Sus scrofa). Epsilon 2010; 18: 1-26.

29. Kornacher, P. Wild boar Sus scrofa damage reductions through large scale management: Applying hunting and feeding as management tools. Epsilon 2006; 6: 1-25.

30. Abbas, M., Khan, S. H., Khan, R. A. and Shahbaz, M. Efficacy of Different Methods to Control Wild Boars: A Perception of Farmers of the Faislabad Division. Pak. J. Agri. Sci. 2004; 41 (3-4): 144-145.

31. West, B. C., Cooper, A. L. and Armstrong, J. B. Managing wild pigs: A technical guide. Human-Wildlife Interactions Monograph 2009; $1: 1$.

32. Thurfjell, H., Spong, G. and Ericsson, G. Effects of hunting on wild boar Sus scrofa behavior. Wildlife Biology 2013; 19 (1): 87-93.

33. Sodeikat, G. and Pohlmeyer, K. Escape movements of family groups of wild boar Sus scrofa influenced by drive hunts in Lower Saxony, Germany. Wildlife Biology 2003; 9: 43-49.

34. Geisser, H. and Reyer, H. U. Efficacy of Hunting, Feeding, and Fencing to Reduce Crop Damage by Wild Boars. The Journal of Wildlife Management 2004; 68 (4): 939-946. 